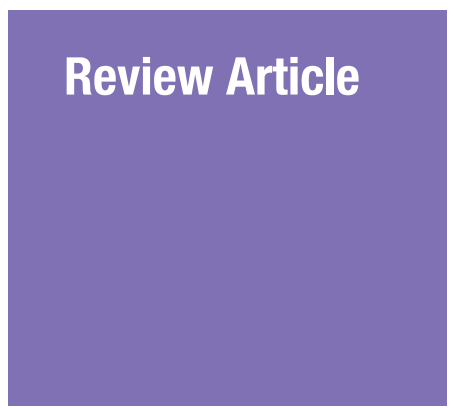

Submitted: 25 Jan 2016 Accepted: 23 Jun 2016 Online: 5 Oct 2016

\section{Role of the Whole Body Vibration Machine in the Prevention and Management of Osteoporosis in Old Age: A Systematic Review}

\author{
Myint Swe1, Biju Benjamin², Aye Aye Tun ${ }^{3}$, Sandheep Sugathan ${ }^{4}$
}

Orthopaedic Unit, Surgical-based Department, University Kuala Lumpur, Royal College of Medicine Perak, Jalan Green town, 30450 Ipoh, Perak, Malaysia

2 Department of Orthopaedics, University Kuala Lumpur, Royal College of Medicine Perak, Jalan Green town, 30450 Ipoh, Perak, Malaysia

3 Department of Pathology, University Kuala Lumpur, Royal College of Medicine Perak, Jalan Green town, 30450 Ipoh, Perak, Malaysia

4 Department of Public Health, University Kuala Lumpur, Royal College of Medicine Perak, Jalan Green town, 30450 Ipoh, Perak, Malaysia

To cite this article: Myint S, Biju B, Aye AT, Sugathan S. Role of the whole body variation machine in the prevention and management of osteoporosis in old age:a systematic review. Malays J Med Sci. 2016;23(5):8-16. http://

dx.doi.org/10.21315/mjms2016.23.5.2

To link to this article: http://dx.doi.org/10.21315/mjms2016.23.5.2

\begin{abstract}
A literature search of related articles was carried out in electronic data sources. Initially, 276 randomised controlled trials related to the title were collected, after which 44 were selected using the keywords. Overlapping articles, articles with a study duration of less than six months, and studies involving young participants were removed from the list. The remaining 20 articles were checked for entitlement using the PEDro scale. A total of nine eligible articles with 1486 participants were analysed. Seven trials used dual-energy x-ray absorptiometry (DXA) to measure bone mineral density (BMD). The six trials published from 2005 to 2013 found a significant increase in BMD. In the remaining one trial, there was no significant increase in BMD. One study published in 2013 reported a significant increase in BMD measured with peripheral qualitative computed tomography, whereas another trial published in 2014 stated that there was a reduction in calcaneal bone density measured by peripheral qualitative ultrasound. From these findings it can be concluded that the whole body vibration machine is a good adjunctive therapy for the prevention and management of osteoporosis in postmenopausal women. However, further investigations are necessary before the same can be recommended for elderly men.
\end{abstract}

Keywords: vibration, bone mineral density (BMD), osteoporosis, elderly

\section{Introduction}

Whole body vibration (WBV) is defined as a vibration transmitted to the body through the feet or seat. It is a well-known fact that prolonged exposure to vibration has an unfavourable effect on health in humans and is considered as a kind of occupational hazard. Back pain as a result of osteoporosis is a common problem among bus drivers and operators of heavy equipment, such as forklift trucks, agricultural tractors, and earth-moving machinery. Effects on the skeletal systemespecially osteoporosis of the lumbar spine-and on the nervous system are mainly seen in people who are exposed to intense WBV for a prolonged duration, and there may be minor effects on the gastrointestinal tract, female reproductive 
organs, body balance, and cervical spine (1). Dental surgeons and workers using hand-held drilling machines are exposed to excessive hand-transmitted vibration and may develop a disorder called hand-arm vibration syndrome, with symptoms and signs related to the vascular, neurological, and musculoskeletal systems of the upper limb. In a comparative study of 43,000 workers who were exposed to long-term WBV and 24,000 controls, WBV was associated with increased risk to the spine and the peripheral nervous system (2).

The World Health Organisation defines osteoporosis as a condition of reduced bone mineral density (BMD) by 2.5 standard deviations below the T score (average BMD for healthy young women). Osteoporotic bones are fragile and are at increased risk of fracture.

Generally speaking, bone is a dynamic structure that usually responds to mechanical stimuli. The activities of daily living, as well as walking and other forms of exercise, contribute a mechanical stimulus that can maintain or increase BMD. Forces of gravity and muscle forces during daily activities, as well as the ground reaction force resulting from running and jumping, are major contributors to bone modelling and remodelling (3). Therefore, increased physical activity is necessary to maintain or increase BMD.

Everybody reaches peak bone mass between the ages of 30 and 35, after which bone mass gradually declines. Although osteoporosis is caused by many factors, such as age, sex, nutrition, smoking, and hormonal changes in postmenopausal women, physical activity plays an important role in maintaining bone mass or reducing the rate of bone loss. However, it is not easy for older or debilitated persons to have active lifestyles, nor is it possible for those with neurological or severe joint problems. For such individuals, WBV machines may be helpful in maintaining BMD or reducing the rate of bone loss.

At the present time, many types of WBV machine are available in the market and it is claimed that they are good for osteoporosis, as well as for weight reduction.

Although the treatment of osteoporosis relies on bisphosphonate compounds as a standard and denosumab as an effective alternative (4), the WBV machine can be effective in the nonpharmacological supportive management of osteoporosis. Therefore, in this study we analysed the articles related to WBV machines to ascertain whether these machines indeed have a favourable effect on osteoporosis.

\section{Methodology}

This was a systematic review of randomised controlled trials.

\section{Inclusion criteria}

Randomised control trials (RCTs) studying the effect of WBV machines and BMD/ osteoporosis in old age.

\section{Exclusion criteria}

1. RCTs involving animals

2. RCTs involving young people

3. All non-RCTs

\section{Time limit}

The researchers studied articles published during the years 2010 to 2015 .

\section{Operational definitions}

\section{Definition of vibration and WBV therapy}

A vibration is a movement that repeats or oscillates around an equilibrium point (5). Vibration is measured by frequency and amplitude or magnitude. Frequency is the number of oscillations per second, expressed in hertz $(\mathrm{Hz})$. Amplitude is the height of the wave, expressed in millimetres ( $\mathrm{mm}$ ). Magnitude is a combination of amplitude and acceleration. It is calculated using the following formula:

$$
\mathrm{M}=2 \times \pi^{2} \times \mathrm{F}^{2} \times \mathrm{A},
$$

where $\mathrm{M}=$ Magnitude, $\mathrm{F}=$ frequency $(\mathrm{Hz})$, and $\mathrm{A}=$ amplitude, or peak to peak displacement (6).

The effect of vibration upon the body is determined mainly by these two factors, but the responses of different tissues to vibration are not the same. Collagen responds to a slow pulse of $4 \mathrm{~Hz}$ (four pulses per second) and muscles respond to frequencies between 30 and $50 \mathrm{~Hz}$; $30 \mathrm{~Hz}$ is the best (7) for stimulating bone growth. Other factors that have an effect on BMD are the duration of WBV exercise and the posture/ position on the WBV platform (8).

\section{Different types of WBV machine}

WBV machines come in different brands. However, the mechanism for transmitting 
vibration to the body is different. There are two ways of providing vibration. One is vertical displacement and the other is oscillatory alternating displacement (6). There is also a difference in the variation of amplitude and frequency of vibration, with a range of 1-22 $\mathrm{mm}$ for amplitude and $5-25 \mathrm{~Hz}$ for frequency.

In 2009, Merriman and Jackson (9) identified five articles related to the effect of WBV machines on BMD (10, 11, 12, 13, 14). The authors noticed that four studies had shown significant improvement or maintenance of BMD at the hip or tibia following use of the WBV plate, compared to other forms of exercise. However, there were differences in the magnitude of vibration (0.2-10 g) and in the exposure time. The authors suggested that further studies were needed to determine the optimal magnitude, frequency, and duration of exposure to WBV machines to obtain optimal results.

In 2010, Slatkovska et al. (15) published a systematic review and meta-analysis of eight articles. They found that there was a small, but significant improvement of bone mineral density (BMD) in the hip, but only in postmenopausal women, and in the tibia and spine, only in children/adolescents but not in young adults. The investigators agreed that WBV was a promising new modality, but suggested large-scale long-term studies were needed to determine the optimal magnitude, frequency and duration (15).

Therefore, we performed a systematic analysis of RCT articles published during the years 2010 to 2015 related to the effects of WBV exercise on bone density, in the hope of throwing some light on this issue (see Table 1).

\section{Trials of WBV therapy for osteoporosis}

1. Verschueren et al. (16) published an online article in July 2010. It was an RCT with a $2 \times 2$ factorial design involving 113 elderly postmenopausal women (mean age 79.6 years). Participants were divided into four groups: two groups with WBV exercise, who received either a conventional or a high dose of vitamin D3, and two groups without WBV exercise, who received only the conventional or high dose of vitamin D3. WBV exercise included exposure to $1.6-2.2 \mathrm{~mm} \times 30-40$ $\mathrm{Hz}$ for 1-12 minutes, 3 times per week for 6 months. The authors found that there was an improvement in the bone mineral density of the hip after 24-weeks of the WBV programme in all four groups. WBV exercise did not result in any additional effect.
2. In the Erlangen Longitudinal Vibration Study (ELVIS), von Stengel et al. (17) observed that any exercise programme had a positive effect on BMD in the lumbar spine, but the addition of WBV exercise did not enhance the positive effect. In this study, 151 postmenopausal women were randomly assigned to three groups: a conventional training group (TG), a conventional training with vibration group (TGV), and a control group (CV). The TGV group was exposed to conventional exercises as well as 15 minutes of exposure to vibration $(1.7 \mathrm{~mm} \times 25-35$ $\mathrm{Hz}$ ). After 18 months, BMD was measured. There was an increase in BMD in the lumbar spine (TGV 1.5\%, TG 2.1\%), but not in the hip.

3. The ELVIS II, published in 2011 by von Stengel et al. (18), studied the effects on BMD of WBV training using different devices. A total of 108 postmenopausal women were randomly assigned to three types of exercise, including (a) rotational vibration training (RVT) $12.5 \mathrm{~Hz} \times 12 \mathrm{~mm}$, 15 minutes $\times$ three times/week, (b) vertical vibration training (VVT) $35 \mathrm{~Hz} \times 1.7 \mathrm{~mm}$, 15 mins 3 times/week, and (c) wellness control training. BMD was measured in the lumbar spine and hip at baseline and after 12 months. The investigators concluded that WBV effectively increased the BMD of the lumbar spine, but not the hip, in both RVT and VVT groups relative to the control group.

4. Zha et al. (19) carried out an RCT that included 53 elderly people (11 male, 42 female, age $>65$ years, mean $=77)$ and 15 adults (4 male, 11 female, age 50-60 years, mean $=55$ ) in February 2012. Participants were randomly assigned to a WBV with alternative tilting (WBVAT) group or to a control group. The WBVAT group was exposed to vertical vibration ( $0.5 \mathrm{~g}-0.8$ g, $45 \mathrm{~Hz}-55 \mathrm{~Hz}$ ) and alternative tilting for 20 mins per day, three days a week, for six months. After six months of training with WBVAT, there was a significant increase in BMD in the lumbar spine $(2.52 \%)$ and in the femoral neck (3.22\%) for elderly individuals of both sexes. The increase in the BMD of adults was $1.63 \%$ for the spine and $2.05 \%$ for the femoral neck. 
Review Article | Nigella sativa tharapeutics in cannabis neurotoxicity

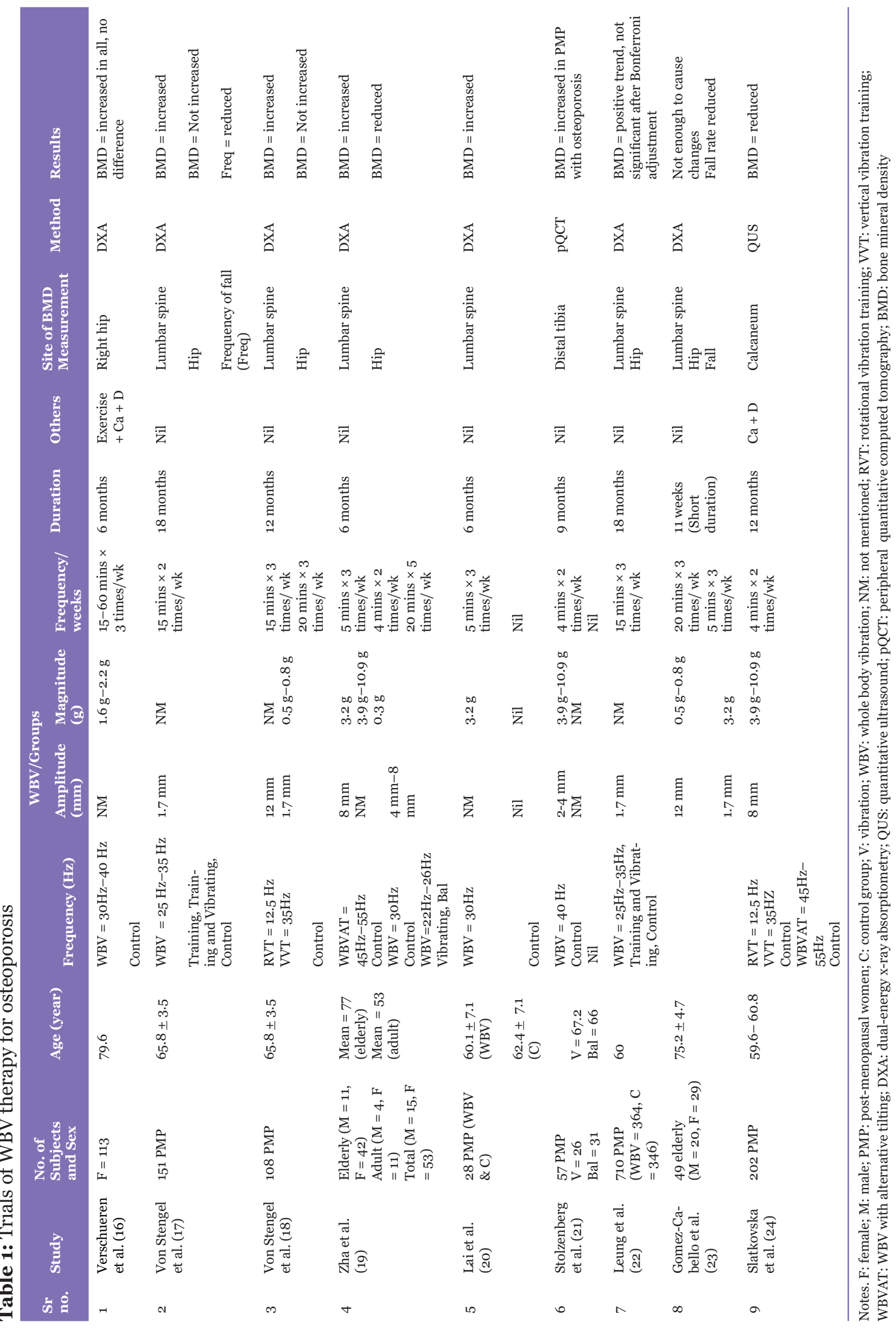


5. In a randomised control trial by Lai et al. (20), published in 2013, 28 postmenopausal women were randomly divided into a WBV group and a control group. After receiving the 6-month intervention of high-frequency (30 Hz) and high-magnitude (3.2 g) WBV in a natural full-standing position for 3 mins, 3 times per week, the BMD of the WBV group had significantly increased by $2.032 \%$, whereas there was a $0.046 \%$ decrease in the control group ( $p=0.016)$.

6. Stolzenberg et al. (21), in 2013, randomly divided 57 post-menopausal women with osteopenia into two groups: one group underwent a resistive exercise programme with WBV exercise and the other were given balance training. The WBV group was exposed to vibration exercise (amplitude $2 \mathrm{~mm}-4 \mathrm{~mm}$, frequency 22-24 $\mathrm{Hz}$ ) for four minutes, twice weekly for nine months. Peripheral quantitative computed tomography measurements found a significant increase in BMD in the distal tibia.

7. A cluster-randomised controlled trial, published in March 2014 by Leung et al. (22), investigated the long-term effect of low-magnitude, high-frequency vibration (LMHFV) on the bone quality of 710 postmenopausal females aged over 60 years. A total of 364 participants were exposed to LMHFV ( $35 \mathrm{~Hz}, 0.3 \mathrm{~g}$ ) for 20 minutes, five days per week, for 18 months. Another 346 women participated as controls. BMD was one of the secondary outcomes and was measured after 9 months and 18 months. No significant differences were found in the overall changes in BMD.

8. A study by Gómez-Cabello et al. (23) in 2014 concluded that 11 weeks' use of WBV was not sufficient to cause changes in BMD and only produced a small variation in bone density in elderly people.

9. Slatkovska $(15,24)$ and colleagues randomly assigned 202 postmenopausal women with osteopenia to three groups: one group was exposed to a WBV platform with lowmagnitude vibration, $0.3 \mathrm{~g} \times 90 \mathrm{~Hz}$, another was exposed to $0.3 \mathrm{~g} \times 30 \mathrm{~Hz}$ for $20 \mathrm{mins}$ daily, while the third group served as a control. All participants received calcium and vitamin D. Measurement of the BMD of calcaneal bone was performed after 12 months by quantitative ultrasound (QUS).
Exposure to WBV of $90 \mathrm{~Hz}$ or $30 \mathrm{~Hz}$ for 20 minutes daily for 12 months did not improve any QUS parameters, but there was a small but significant decrease in calcaneal broadband attenuation (BUA).

\section{Discussion}

A study published in 2014 mentioned that there was a small, but significant decrease in calcaneal BUA measured by QUS (24). Most of the studies we analysed used a dual-energy X-ray absorptiometry (DXA) machine to measure BMD, usually in the lumbar spine or hip. Measurement of BMD in the calcaneus using QUS was a new approach that yielded negative results. The exposure was of low magnitude and high or very high frequency. The low magnitude (0.3 g) may be responsible for these bizarre results. Further studies with high magnitude ( $>1 \mathrm{~g}$ ), as in other studies, would be needed to support the findings.

In one study of 113 postmenopausal women, there was an increase in BMD in both WBV groups as well as the control group, which was treated only with calcium and vitamin $\mathrm{D}$. The author concluded that there was no additive effect from using the WBV machine. (16)

In another study of 710 post-menopausal women, using low-magnitude high-frequency vibration (LMHFV) for 18 months, the author stated that the BMD of the hip and spine showed a positive trend in the vibration group compared to the controls (mean between-group difference $1.43 \%$ for femoral neck, $1.12 \%$ for spine) (22). The author concluded that the effect was not statistically significant after Bonferroni adjustment. In this study, the primary outcome was body balance and fracture risk, while BMD was a secondary outcome. The low magnitude was likely to be the cause of the insignificant improvement in BMD, even though it showed a positive trend.

Five of the nine trials analysed $(13,14,15$, $16,17)$, which enrolled a total of $404(\mathrm{M}=35$, $\mathrm{F}=369$ ) participants, concluded that there was an improvement in BMD measured by DXA after exposure to WBV machine trials using medium to high magnitude/amplitude with high frequency for a duration of 6-18 months. However, the bone parts used to measure the improvement in BMD were in regions such as the spine, hip, and tibia.

In one trial with 57 participants, peripheral quantitative computed tomography was used 
to measure BMD in the distal tibia and found a significant increase after WBV therapy (21).

\section{Limitations, Suggestions and Conclusion}

The major limitation of this study is the diversity in the use and specifications of WBV machines. Different research groups utilised different frequencies, amplitudes, and magnitudes. For example, some used frequencies of $22-26 \mathrm{~Hz}$, whereas others used $30 \mathrm{~Hz}, 35 \mathrm{~Hz}$, $40 \mathrm{~Hz}, 25-35 \mathrm{~Hz}, 30-40 \mathrm{~Hz}$, or $45-55 \mathrm{~Hz}$ (Table 1). For this reason, it is difficult to determine the ideal frequency of the WBV machine for obtaining the optimum bone-forming effect.

Among the nine research papers included in this systematic review, three articles mentioned the amplitude, three mentioned magnitude, while two others mentioned both amplitude and magnitude. Amplitude varied from $1.7 \mathrm{~mm}$ to 8 $\mathrm{mm}$ and magnitude from $0.3 \mathrm{~g}$ to $10.9 \mathrm{~g}$ (Table 1). Thus, the same problem arises as regards the choice of best amplitude or magnitude.

The site used for measuring BMD also varied from one study to another. Five of the studies measured BMD in both the lumbar spine and hip. The other four studies measured BMD in the hip, lumbar spine, distal tibia, and calcaneus. The major complications of osteoporosis are fractures of the proximal femur and compression fractures in the spine, not fractures of the tibia and calcaneus. Therefore the sites for BMD measurement should be standardised as the femur and lumbar spine.

As $30 \mathrm{~Hz}$ is the best frequency for stimulating bone growth (7), new randomised control trials using $30 \mathrm{~Hz}$ as the standard frequency, with different levels of amplitude/ magnitude, for durations of more than six months, with measurement of BMD in the femur and lumbar spine, are suggested for future research. The method of measuring the BMD must also be DXA, which is the gold standard for the purpose.

This might help to determine the most appropriate levels of amplitude/magnitude for improvement of bone mineral density in the hip and lumbar spine.

In seven studies with $1235 \quad(83.1 \%)$ participants (RCTs 1-7 above; refs. 16-22) it was found that there was an increase in BMD after different amounts of WBV exposure. In some studies whose primary outcomes were body balance and muscle strength, the authors observed positive effects of WBV therapy on those outcomes $(17,21)$.

In conclusion, our group found no strong evidence to contradict the finding that the WBV machine is a good alternative or good additive for the prevention and management of osteoporosis in postmenopausal women.

\section{Acknowledgements}

Authors acknowledge the support, encouragement and trainings provided by University Kuala Lumpur Royal College of Medicine Perak and the guidance and help provided by Librarian of the institution.

\section{Conflict of Interests}

No

\section{Funds}

None

\section{Authors' Contributions}

Conception and design: MS, BB

Analysis and interpretation of the data: MS, AAT, SS

Drafting of the article: MS, BB, AAT

Critical revision of the article for important intellectual content: MS, BB, SS

Final approval of the article: MS, BB

Provision of study materials or patients: AAT

Statistical expertise: SS

Administrative, technical, or logistic support: MS, SS

Collection and assembly of data: MS, AAT

\section{Correspondence}

Dr Myint Swe

MBBS (University of Medicine, Mandalay, Myanmar), MMed. Sc (orthopaedics) (University of Medicine, Mandalay, Myanmar)

Orthopaedic Unit, Surgical Based Department, University Kuala Lumpur, Royal College of Medicine Perak,

No: 3, Jalan Greentown, 30450 Ipoh, Perak, Malaysia

Tel: $+6016-3445106$

Fax:+605-2536637

E-mail:drmsconortho@gmail.com 


\section{References}

1. Bovenzi M. Health risks from occupational exposures to mechanical vibration. Med Lav. 2006; 97:535-541.

2. Seidel H, Heide R. Long-term effects of wholebody vibration: a critical survey of the literature. Int Arch Occup Environ Health. 1986; 58: 1-26. http://dx.doi.org/10.1007/bfoo378536

3. Khan K, McKay H, Kannus P, Bailey D, Wark J, Bennell K (Editors). Physical activity and bone health. Champaign, IL: Human Kinetics; 2001. doi:http://dx.doi.org/10.1136/bjsm.36.1.76-b

4. Benjamin B, Benjamin M, Swe M, Sugathan S. Systematic review on the comparison of effectiveness between Denosumab and Bisphosphonates in post-menopausal osteoporosis. PROSPERO.2015:CRD42015019464. Available from http://www.crd.york.ac.uk/PROSPERO/display_ record.asp?ID=CRD42015019464

5. Wysocki A, Butler M, Shamliyan T, Kane RL. Whole body vibration therapy for osteoporosis: state of the science. Ann Intern Med. 2011; 155: $680-686$.

6. Cardinale M, Wakeling J. Whole body vibration exercise: are vibrations good for you? $\mathrm{Br} J$ Sports Med. 2005; 39: 585-589. doi:10.1136/ bjsm.2005.016857 PMCID: PMC1725325

7. Waggon A.J, Whole body vibration therapy: research packet [Internet]. [cited 26 Apr 2016]. Available from: https://www.vibeforhealth.com/ Data/Default/ WBVTherapyResearchPacket.pdf

8. Totosy de Zepetnek JO, Giangregorio LM, Craven BC. Whole-body vibration as potential intervention for people with low bone mineral density and osteoporosis: a review. J Rehabil Res Dev. 2009; 46: 529-542.

9. Merriman H, Jackson K. The effects of wholebody vibration training in aging adults: a systematic review. J Geriatr Phys Ther. 2009; 32: 134-145. http://dx.doi.org/10.1519/o0139143200932030-00009

10. Gusi N, Raimundo A, Leal A. Low-frequency vibratory exercise reduces the risk of bone fracture more than walking: a randomized controlled trial. BMC Musculoskelet Disord. 2006; 7: 92. doi: http://dx.doi.org/10.1186/14712474-7-92
11. Iwamoto J, Takeda T, Sato Y, Uzawa M. Effect of whole-body vibration exercise on lumbar bone mineral density, bone turnover, and chronic back pain in post-menopausal osteoporotic women treated with alendronate. Aging Clin Exp Res. 2005; 17: 157-163. doi: http://dx.doi. org/10.1007/bfo3324589

12. Russo CR, Lauretani F, Bandinelli S, et al. Highfrequency vibration training increases muscle power in postmenopausal women. Arch Phys Med Rehabil. 2003; 84: 1854-1857. doi: http://dx.doi. org/10.1016/sooo3-9993(03)00357-5

13. Verschueren SM, Roelants M, Delecluse C, Swinnen S, Vanderschueren D, Boonen S. Effect of 6-month whole body vibration training on hip density, muscle strength, and postural control in postmenopausal women: a randomized controlled pilot study. $J$ Bone Miner Res. 2004; 19: 352359. doi: http://dx.doi.org/10.1359/jbmr.0301245

14. Rubin C, Recker R, Cullen D, Ryaby J, McCabe J, McLeod K. Prevention of postmenopausal bone loss by a low-magnitude, high-frequency mechanical stimuli: a clinical trial assessing compliance, efficacy, and safety. $J$ Bone Miner Res. 2004; 19: 343-351. doi: http://dx.doi. org/10.1359/jbmr.0301251

15. Slatkovska L, Alibhai SM, Beyene J, Cheung AM. Effect of whole-body vibration on BMD: a systematic review and meta-analysis. Osteoporos Int. 2010; 21: 1969-1980. doi: http;//dx.doi. org/10.1007/s00198-010-1228-z

16. Verschueren SM, Bogaerts A, Delecluse C, et al. The effects of whole-body vibration training and vitamin D supplementation on muscle strength, muscle mass, and bone density in institutionalized elderly women: A 6-month randomized, controlled trial. J Bone Miner Res. 2011; 26: 4249. doi: http://dx.doi.org/10.1002/jbmr.181

17. Von Stengel S, Kemmler W, Engelke K, Kalender WA. Effects of whole body vibration on bone mineral density and falls: results of the randomized controlled ELVIS study with postmenopausal women. Osteoporos Int. 2011; 22: 317-325. doi: http://dx.doi.org/10.1007/ s00198-010-1215-4

18. Von Stengel S, Kemmler W, Bebenek M, Engelke K, Kalender WA. Effects of whole-body vibration training on different devices on bone mineral density. Med Sci Sports Exerc. 2011; 43: 1071-1079. doi: http://dx.doi.org/10.1249/ mss.obo13e $318202 f_{3} d_{3}$ 
Review Article | Nigella sativa tharapeutics in cannabis neurotoxicity

19. Zha DS, Zhu QA, Pei WW, et al. Does whole-body vibration with alternative tilting increase bone mineral density and change bone metabolism in senior people? Aging Clin Exp Res. 2012; 24: 2836. doi: http://dx.doi.org/10.3275/7517

20. Lai CL, Tseng SY, Chen CN, et al. Effect of 6 months of whole body vibration on lumbar spine bone density in postmenopausal women: a randomized controlled trial. Clin Interv Aging. 2013; 8: 1603-1609. doi: http;//dx.doi. org/10.2147/CIA.S53591

21. Stolzenberg N, Belavý DL, Beller G, Armbrecht G, Semler J, Felsenberg D. Bone strength and density via pQCT in post-menopausal osteopenic women after 9 months resistive exercise with whole body vibration or proprioceptive exercise. $J$ Musculoskelet Neuronal Interact. 2013; 13: 66-76.

22. Leung KS, Li CY, Tse YK, et al. Effects of 18-month low-magnitude high-frequency vibration on fall rate and fracture risks in 710 community elderly: a cluster-randomized controlled trial. Osteoporos Int. 2014; 25: 17851795. doi: http://dx.doi.org/10.1007/soo198-0142693-6

23. Gómez-Cabello A, González-Agüero A, Morales S, Ara I, Casajús JA, Vicente-Rodríguez G. Effects of a short-term whole body vibration intervention on bone mass and structure in elderly people. $J$ Sci Med Sport. 2014; 17: 160-164. doi: http://dx.doi. org/10.1016/j.jsams.2013.04.020

24. Slatkovska L, Beyene J, Alibhai SM, Wong Q, Sohail QZ, Cheung AM. Effect of whole-body vibration on calcaneal quantitative ultrasound measurements in postmenopausal women: a randomized controlled trial. Calcif Tissue Int. 2014; 95: 547-556. doi: http://dx.doi. org/10.1007/s00223-014-9920-1 


\section{Appendix}

Figure 1: Search Summary
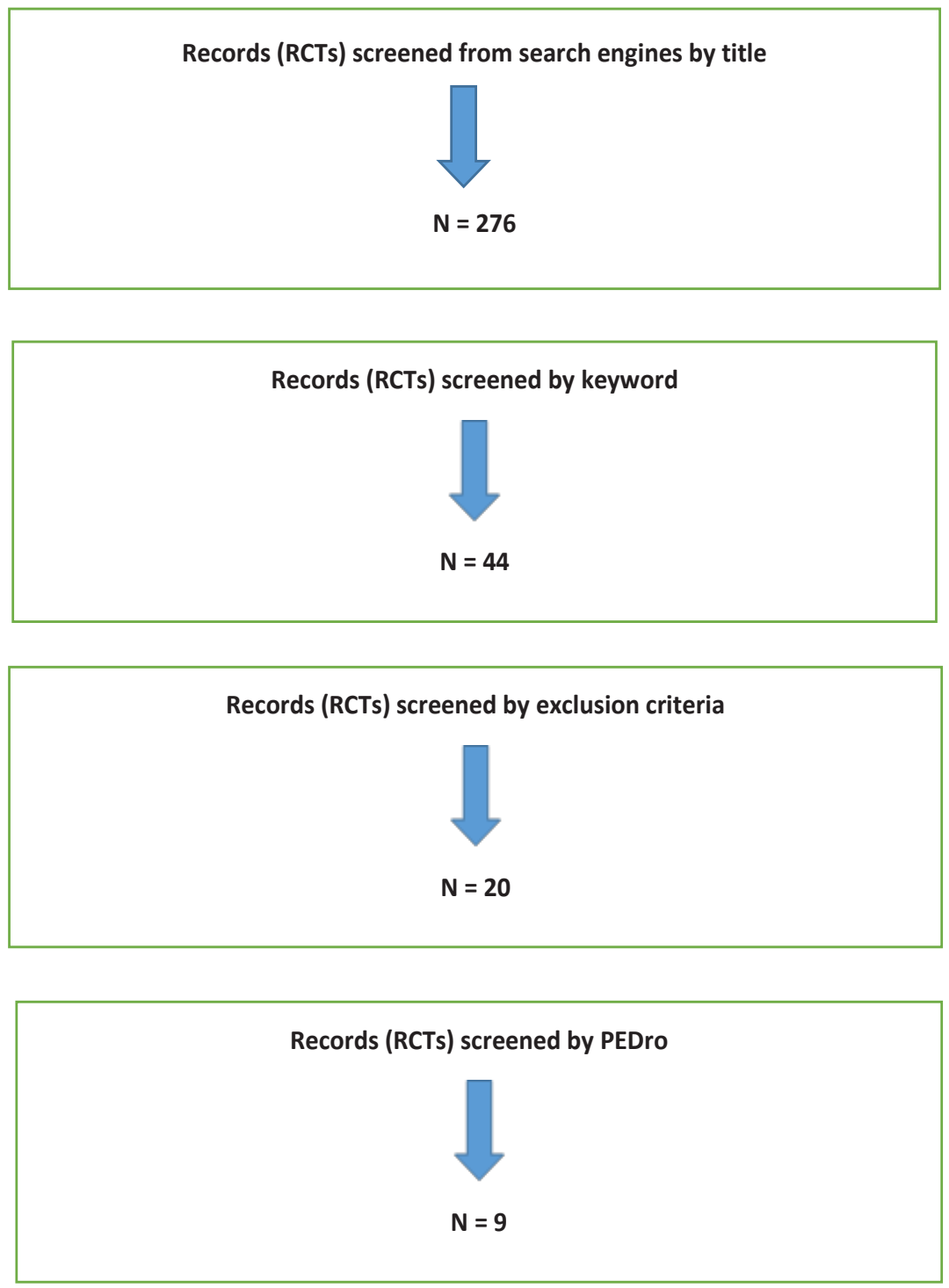